\title{
Status of Women and Fertility in Pakistan
}

\author{
Ali Muhammad \\ Department of Sociology and Criminology \\ St. Mary's University \\ Halifax, Nova Scotia, Canada \\ E-mail: ali.muhammad@,smu.ca
}

\section{Rajulton Fernando}

Department of Sociology

University of Western Ontario

London, Ontario, Canada

\begin{abstract}
As argued, low status of women is associated with high fertility. Yet, it is the most neglected area in fertility studies because of measurement complications. The concept itself needs clarification since there is no universal definition. Despite these complications, utilizing fourteen theory driven indicators, this study attempts to measure the status of women in Pakistan and examines its relationship with fertility. Structural Equation Models are used to measure status and Path Models to examine its association with fertility. The results confirm a negative association between status of women and fertility in Pakistan.
\end{abstract}

Key Words: Status of women, fertility, determinants of fertility, Status of women in Pakistan, status of women and fertility. 


\section{Résumé}

Tel que maintenu, un statut peu élevé de la femme est relié à une forte fécondité. Or, ceci représente la dimension la moins étudiée dans les études de fécondité à cause des complications au niveau des mesures. Le concept même requiert d'être clarifié puisqu'il n'existe aucune définition universelle. En dépit de ces complications, cette étude tente de mesurer le statut de la femme au Pakistan ainsi que sa relation avec la fécondité en se servant de quatorze indicateurs guidés par théorie. Nous avons utilisé des modèles par équation structurelle pour mesurer le statut et des modèles de pistes causales pour examiner sa relation avec la fécondité. Les résultats confirment qu'au Pakistan, une corrélation négative existe entre le niveau du statut des femmes et leur fécondité.

Mots clés: Statut de la femme, fécondité, déterminants de la fécondité, statut des femmes au Pakistan, statut des femmes et fécondité.

\section{Concept and Measurement of Status of Women}

It is generally hypothesized that status of women is negatively associated with fertility, low status of women is likely to be a vital factor in keeping fertility levels high in Pakistan. Measuring status of women and examining its relationship with fertility, however, is fraught with many methodological problems because of lack of universally acceptable definition of the concept and because of lack of proper indicators to measure it. Religious obligations and traditional practices add further to the complexity and controversy surrounding the definition (Whyte 1978). For instance, in Asian cultures, the position of a new bride is quite different from the position of her mother-in-law (Mason 1986), it is lower for new brides. Despite such definitional complications and measurement issues, this study aims at measuring status of women in Pakistan and examines its relationship with fertility. The objective is to contribute to the existing literature a methodologically more meaningful way of measuring status of women and to examine its impact on fertility.

Generally, the term "status" refers "to the position or positions a person or group holds in the social structure of a society - in its educational institutions, in its occupational structure, in its political system, in the family, and so on" (UN 1975: 4). According to this view, status of women refers to the position a woman occupies as a worker, as a student, as a wife, as a mother, as a political

CSP 2010, 37.1-2: 1-23 
leader, and so on. It also refers to whatever power and prestige are attached to these positions and to the rights and duties a woman is expected to exercise in her active role as occupant of these positions. Specifically, the concept of status of women has been elucidated in the literature in terms of four dimensions: a) Resources: referring to access and control over economic resources, b) Autonomy, c) Power: referring to participation in household decision-making, and d) Gender Equity or equal opportunities for men and women.

The resources dimension of women's status encompasses the degree of access and control women have over material resources (including food, income, land, and other forms of wealth) and over social resources (including knowledge, power and prestige) within the family, in the community, and in a society (Dixon 1978; Curtin 1982). Bradley and Khor (1993: 349) conceptualized this as economic dimension of women's status encompassing their involvement in "the activities and institutions constructed around the production, distribution and consumption of goods and services" and "women's paid employment and access to and control of economic resources." Women's employment thus can be seen as an improvement in their status, however, most women in Pakistan are engaged in low paid jobs (unskilled) because of "economic need" which may not improve their status (Wasim 2002).

Women's autonomy is one of the most commonly used and cited criteria to measure the status of women. Yet, it is a murky, multidimensional concept and is defined in more ways than one. In its simplest form, Birdsall and Chester (1987) considered women's education level and wage rates relative to those of men as indicators of autonomy. More specific attributes were added over the years. Mason and Smith (2000) used six indicators to measure women's "autonomy". These indicators include: women's say in economic decisionmaking, women's say in fertility related decisions, women's ability to move around and outside the home, and other indicators that refer to interpersonal power relations between women and their husbands. Hindin (2000) defined autonomy as the capacity to manipulate one's personal environment. Broadly speaking, autonomy refers to technical, social, and psychological ability to obtain information and to use it as the basis for making decisions about one's private concerns and those of one's intimate circle. In short, autonomy is the ability to control oneself, including one's own reproductive life.

Power is seen as women's ability to participate in household decisionmaking including such mundane day to day decisions about clothing, food, recreation, education and treatment of sick children as well as decisions concerning their reproduction. Participation and control over such decisions is presumed to give women authoritative power and raise their status in the household. Some scholars (e.g., Hindin 2000), however, distinguish women's status from women's power. They argue that "women's status refers to the women's overall position in the society while power refers to women's ability to influence and control at the interpersonal level." Power is also seen at times as 
the ability to determine important events in their lives and the ability to control or change other women's and men's attitudes and behaviors.

Gender equity refers to the right of equal participation for both men and women in a range of social, economic, political and cultural activities of the household and of the communities where they live. These activities include equal opportunities of employment and access to education and health facilities, right to vote and right to participate in general elections. The discrimination that exists in some Asian cultures regarding the nutritional requirements of a baby boy versus a baby girl can be considered as discrimination against women or as lack of gender equity (Ram 1993). The unequal distribution of roles in different spheres of life gives disproportionate power to men, and women hold subordinate positions which not only affect their routine decisions but also decisions regarding fertility.

In addition to these four dimensions, Bradley and Khor (1993: 349) included "political" and "social" dimensions as well. According to them:

"The political dimension represents the articulation of power relationships, conceptualized as the subjugation of one group by another. The extent of women's participation and representation in the state apparatus and women's power in the household decisions are observable manifestations of variations in power and authority relationships."

"The social dimension includes activities and institutions such as education, kinship, and the mass media, which constitute the symbolic infrastructure in a society. Examples of indicators of the social dimension of status include women's educational attainment, the objectification of women ${ }^{1}$, and women's kinship roles and obligations."

Other suggestions for indicators of women's status abound in the literature. Epstein (1982) suggested women's prestige as a good indicator of their status, Dyson and Moore (1983) suggested women's power or freedom especially within the family or household as good indicators. Boehmer and Williamson (1996) used five indicators - gender equality, age at first marriage, contraceptive prevalence, fertility and crude birth rates - as measures of women's status in LDCs. Mason (1986: 295) grouped various indicators into three broad categories: the demographic indicators, kinship-family indicators and economic indicators. Among the demographic indicators, Mason included the difference between male and female mortality rates, female age at marriage, average age difference between husband and wife, and parental preference for male children. Some of the kinship-family indicators are: purdah, polygyny, female property inheritance, dowry and arranged marriages.

CSP 2010, 37.1-2: 1-23 
Viewing women's status in terms of politics and laws, education, economy, social recognition, and power, Curtin (1982) suggested the following as possible indicators: educational attainment, the extent of legal rights to exercise personal freedom, property ownership and inheritance. Balk (1994) suggested a different set of indicators based on ideas of mobility, authority, attitudes, and leniency of household members towards women. Mobility can be measured by women's ability to move about freely and autonomously in public. Leniency can be measured by a woman's perception about what her family permits her to do. Authority can be measured by a woman's participation in household decisions, and finally attitudes by women's opinions about their rights in general.

\section{Status of Women and Fertility: Theoretical Perspective}

Generally, it is hypothesized that "low women's status leads to high fertility and high women's status leads to low fertility" (McDonald 2000: 429). Wasim (2002: 122) considers that "the contamination of population growth is not merely a function of couple protection or contraception, but it is directly correlated with status of women in Pakistan..." However, Balk (1994) considered women's status, in all its facets, as both a cause and a consequence of fertility. Jejeebhoy (1991) argued for an indirect relationship between status of women and fertility; she argues that women's status affect fertility only indirectly through supply of, demand for and costs of fertility regulation.

Regarding the relationship between women's access to economic resources and fertility, it is obvious that women's limited access to economic resources reduces "the economic bargaining power of individual women within the family, thus making it possible for husbands to impose their own family size decisions on wives" (Folbre 2002: 208). A direct as well as an indirect relationship between autonomy and fertility has been suggested by many authors (such as, Balk 1994; Morgan and Niraula 1995; Basu 1996; Cleland, Kamal, and Sloggett 1996; Visaria 1996; Schuler, Hashemi, and Riley 1997). Women's autonomy can be linked with couples' intentions, attitudes, and behavior in family planning and reproduction (Hindin 2000) which help to reduce fertility, at least when other conditions favor this change (Mason and Smith 2000). Empirically, however, Vlassoff (1996) found an insignificant relationship between women's autonomy and the desired number of children.

Talking about the relationship between women's participation in household decisions and fertility, Hindin (2000) argued for a strong relationship. The women who live in households where they have no input into household decisions are less likely to engage in fertility-limiting or spacing behaviors. Highlighting the importance of women's decision-making power in the household, McDonald (2000) proposed that women's greater decision-making 
power alone could bring fertility to low levels without major changes in women's lives outside the home.

As early as 1975, the United Nations considered gender equality as a major force in fertility reduction. But it was only in 1994, the International Conference on Population and Development stressed the importance of gender equality in achieving lower fertility levels in less developed countries (McDonald 2000). This is because the degree to which women are able to exercise equal rights with men has a major influence on freedom of choice regarding a desirable family size and effectiveness of family planning programs. In contrast, 'patriarchal oppression' constrains the freedom of reproductive choice (Folbre 2002: 207).

Virtually no society in the world provides women completely equal status with men. Women have limited opportunities in most spheres of economic and social activities in different cultures. Even within the household, the position of women may be different depending on her relationship with other household members. Pakistan is a patriarchal society where women have restrictions on spatial movement outside the home, limited decision making power within the household, low autonomy and control over their lives (Sathar and Casterline 1998; Jejeebhoy and Sathar 2001). In general, Pakistani women have a subordinate position in all spheres of life that limits their hold on economic resources. They lack participation in household decision-making and their mobility is restricted to their home environment which may impinge on access to knowledge and technology necessary to control their own fertility. Such a low status imposes restrictions on independent decision-making in most spheres of life including timings and total number of births.

Few attempts have been made by demographers to establish a relationship between fertility and status of women in Pakistan. In 1988, Sathar and her colleagues attempted to relate fertility changes with status of women in Pakistan. They considered, among other factors, women's education, employment and age at marriage as indicators of women's status and concluded that these factors were important determinants of fertility. In 2001, Sathar and Jejeebhoy attempted to measure women's autonomy for cross-cultural comparisons between India and Pakistan and proposed that women's decision-making power, free mobility, freedom of threat from husband, and access and control over economic resources as indicators of women's autonomy. Studies like these have used these indicators separately as if each indicator has its own distinct impact as "status". The problem is that status of women is a multidimensional concept; it has to be construed that way in order to encompass all of the different indicators into a single measure. This study therefore aims to measure status of women as a latent variable, hidden beneath available manifest indicators and then to use it to examine its impact on fertility.

CSP 2010, 37.1-2: 1-23 


\section{Data and Analytical Methods}

The present study utilizes the Pakistan Fertility and Family Planning Survey (PFFPS) conducted in 1996-97. This survey was undertaken by the National Institute of Population Studies (NIPS) with the collaboration of London School of Hygiene and Tropical Medicine (LSHTM) and the UK Department for International Development (DFID). This is a national representative survey which provides information on 8002 households from all four provinces. Individual information on educational attainment, health status, employment, maternity history, reproductive health, and family planning practices were collected from women in their reproductive ages 15-49 years.

This study examines the relationship between status of women and fertility in two steps. In the first step, the unobserved or latent variable "status of women" was measured by a Structural Equation Model (more specifically, by confirmatory factor analysis) and latent scores on status were extracted by using a two-factor model as follows (see Figure 1). The fourteen manifest indicators collected in the PFFPS were themselves assumed to be manifestations of the intermediate five latent dimensions of the ultimate latent multidimensional construct "status of women". These five dimensions were: economic (econ), human capital (hcap), family planning decision ( $f p d$ ), household decisionmaking ( $h d e c$ ) and mobility (mobil). In the second step, a path model of fertility was built using the latent scores on status of women as a continuous variable along with other manifest variables (or covariates).

The latent dimension econ was captured by three manifest indicators: respondent's occupation (ROCC), working at home or away from home (WHAWAY) and possession of money she earns (KEEPM). Among these indicators, some ambiguity is inevitable with work status in Pakistan in that work does not necessarily imply higher status of women. For example, manual laborers might have lower status than those upper class women who do not work at all (because of their affluence). Therefore, some caution needs to be exercised with the work status variable. However, working at home or away from home may be a better indicator since we can expect those who work outside home to have higher economic status compared to those who do not work at all or work within the household. Similarly, we can assume that those women who can keep all the money they earn have higher status than those who cannot. Combining the two indicators, we can hypothesize that women who do not work and, if they work, cannot keep the money they earn will have lower status.

The latent dimension $f p d$ was captured by three manifest indicators: family planning discussion with friends and neighbors (FPDWFN), family planning discussion with anyone (FPDANY) and family planning discussion with spouse (FPTALWH). The last indicator can be assumed to relate closely with the concept of gender equality. In a patriarchal society, the courage to speak about any matter, especially family planning matters with one's spouse, 
cannot but imply boldness to step out of tradition and an outgoing character, which can only be associated with higher status. Family planning discussion with spouse also reduces the communication gap between husband and wife on intimate matters. This possibly would increase gender equity which in turn enables women to decide for themselves whether to have additional children and thus maintain a desirable number of births (McDonald 1997; McDonald 2000). A woman's ability to discuss family planning with her spouse also increases the likelihood of control over her own fertility by averting forced, mistimed or unwanted pregnancies which, according to Hardee and Leahy (2008), accounts for 24 percent of total births.

The latent dimension hcap was measured by three manifest indicators: women's level of education (REDU), their husbands' level of education (HEDU) and husbands' occupation (HOCC). Women's education alone has been considered as an important indicator of status because of self-reliance, awareness of personal freedom, and dignity that education engenders. Husband's educational attainment can also be linked to a woman's status as educated men are more likely to think and behave rationally with their wives and thus enhance their status. Educated husbands are more likely to be aware of women's rights and encourage their participation in household decision-making including the number of births. Husband's education is likely to reduce the communication gap between spouses by providing more opportunities for discussion and communication. In Pakistan, women's status is also closely related to their husbands' occupation, as the wives of high status men also have high status in the society. These women are recognized by their husbands' title and acquire confidence and power not only in the family but also in the society.

The power or authority as a household decision-maker is likely to improve women's position in the household, develop self-confidence, enable them to speak for their rights, and influence decisions in various matters including fertility. This is of particular importance in Pakistan because women are taught to be obedient to their husbands and other elders in the household. Lack of decision-making and independence may easily translate into a woman's inability to decide not only with respect to when and how many children to have but also with respect to very mundane daily tasks. The PFFPS collected some information on these basic daily decisions: final decision about food (DFOOD), final decision about treatment (DTRT) and final decision about clothing (DCLOTH). These three indicators were used to capture the latent dimension hdec.

Finally, women's mobility is likely to open a window to the outside world that could encourage their activities outside the household to reach health care facilities available in their village (Hardee and Leahy 2008) and their participation in activities other than reproduction. According to Hardee and Leahy (2008), "only 15 percent of rural women had been outside their village in the previous month without being accompanied by another adult." Free

CSP 2010, 37.1-2: 1-23 
movement thus can increase the likelihood of having greater awareness regarding fertility decisions. To measure the latent dimension mobil, two indicators - one dealing with women's ability to go to hospital or clinic to seek medical treatment (CGOHOS) and the other with her free movement unaccompanied by an adult (CGOUT) - were included in the model ${ }^{2}$.

The grouping of the above indicators to measure the intermediate latent dimensions of women's status was based on the loadings extracted from exploratory factor analysis. In the confirmatory factor analysis, initial estimation was carried out in accordance with the hypothesized relationships between the intermediate latent dimensions and their manifest indicators. Some paths, however, were added according to the suggested modification indices by LISREL to improve the model fit. The final results, standardized measurement and structural coefficients are presented in Figure 1.

\section{Results}

The overall goodness of fit of a hypothesized Structural Equation Model depends upon the closeness of estimated and observed covariance matrices. If these two covariance matrices are close, the model is considered to represent the data adequately. The fitness of the model is evaluated by different fit indices, the first being the chi-square $\left(\chi^{2}\right)$ goodness of fit index and its level of significance. A small and statistically non-significant chi-square indicates a good fit of a model. However, large samples seriously affect this measure and this criterion hardly holds true. Therefore, the goodness of fit is also assessed on the basis of other available fit indices. The Goodness of Fit Index (GFI), Adjusted Goodness of Fit Index (AGFI), Normed Fit Index (NFI) and Root Mean Square Error of Approximation (RMSEA) are the most commonly used indices among them. In our case, because of large sample size, the final model does not satisfy the criterion of non-significant chi-square for goodness of fit. However, the model has reasonable values of GFI, AGNFI, NFI and RMSEA required for an overall goodness of fit.

As seen in Figure 1, respondents' occupation (ROCC) and working at home or away from home (WKHAWAY) are the most important indicators of the latent dimension econ (their standardized coefficients are the largest). Family planning discussion with anyone (FPDANY) appears as the most important indicator of the latent dimension $f p d$. Both the woman's and her husband's educational attainment are important indicators of the latent dimension hcap. However, woman's own education holds a priority. As for the latent dimension $h d e c$, two indicators - decision about food (DFOOD) and decision about treatment (DTRT) - are found to be more important than decision about clothing (DCLOTH). Finally, women's freedom to visit hospitals serves as a better indicator for the latent dimension mobil.

CSP 2010, 37.1-2: 1-23 
Figure 1

Standardized Coefficients of the Two-Factor Model - Women Aged 15-49, Pakistan Fertility and Family Planning Survey 1996-97

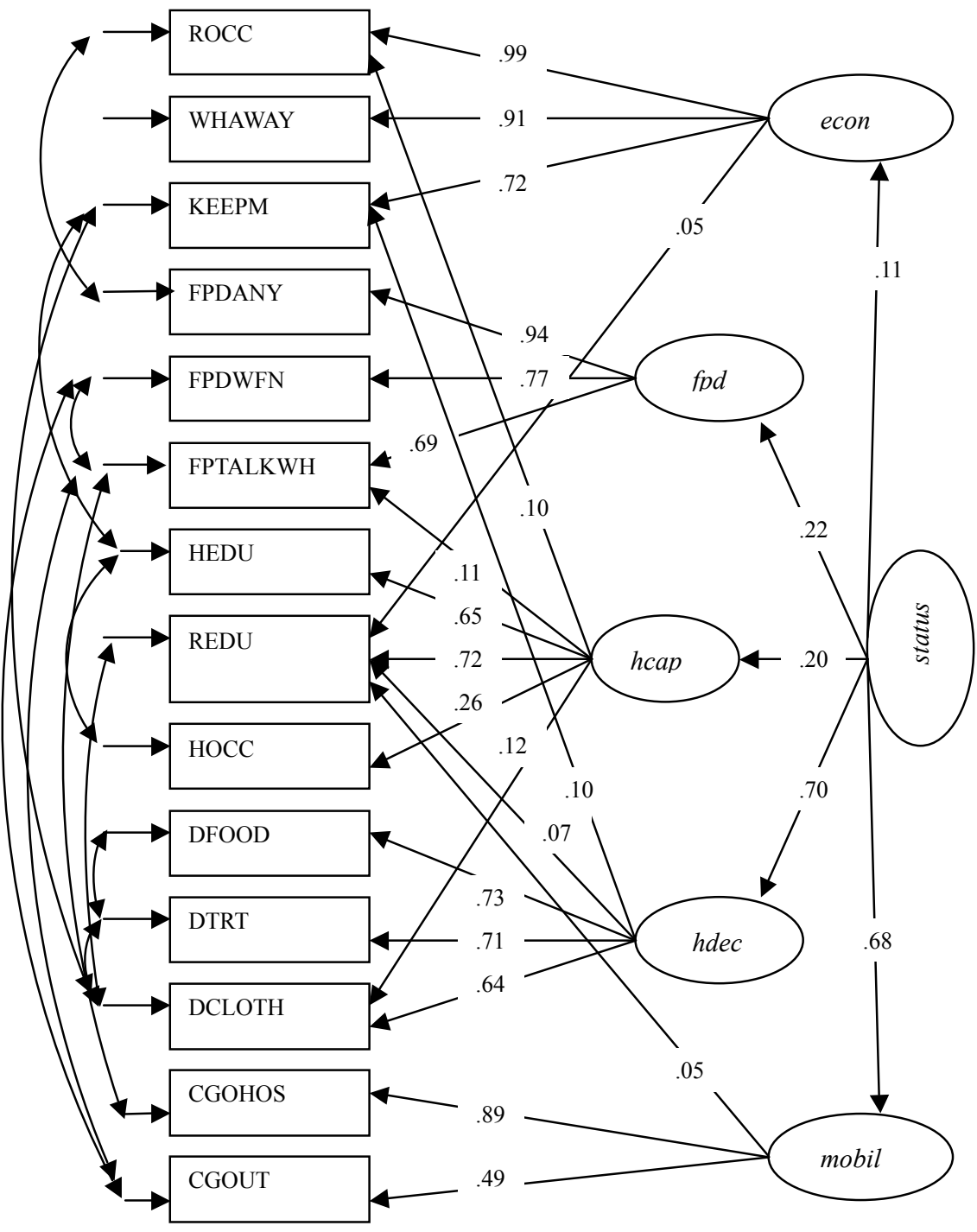

Chi-Square $=98.08, \mathrm{df}=48, \mathrm{P}$-value $=0.00003, \mathrm{RMSEA}=0.012$ 
Moving forward from these intermediate latent dimensions to the ultimate latent variable status reveals that only two latent dimensions, hdec and mobil, finally matter in measuring the status of women. Their standardized coefficients are in the range of 0.70 while the other three latent dimensions have values far below our expectations from what we read in the literature. It is all the more astonishing that the economic dimension is the least important of all the five dimensions of women's status considered in this study. This shows that women's status, at least in the case of Pakistan, is ultimately defined by its social aspects, even through such banal activities like moving around and deciding about daily food and clothing. In other words, women's status is ultimately defined by their decision-making power (even in daily household chores) and their free mobility (to go out alone on their own, unaccompanied by adults).

Thus, the findings support the argument that those women who participate in household decisions and have no restrictions on their mobility are likely to be better off than those who do not. Although it is surprising that the economic dimension is the least important for the status of women in Pakistan, two possible reasons can be given for this finding. The first is the proportion (or sample size) of working women in Pakistan: only 25 percent of women work and only 20 percent work for money. The second is the cautionary note mentioned in the introductory section of this paper, namely that women's status in Pakistan cannot necessarily be associated with their work status. Women in "prestigious" jobs are likely to have higher status but women who work as laborers may have lower status than women who do not work at all because women who work as laborers are likely to be forced to work for financial reasons. Thus, it is not necessarily true that working women will have higher status. And, the idea of work status going hand in hand with women's status is plagued with ambiguity in a patriarchal society like Pakistan. In such contexts, women's employment assumes much less important role than simple activities in which women are engaged in their daily lives.

\section{Status of Women in Pakistan}

It may be useful to examine the latent scores on status of women extracted from the fourteen indicators used in the confirmatory factor analysis. Table 1 shows the descriptive statistics on these latent scores for selected covariates. These scores were categorized into low, medium and high using cut-off points at the three quartiles. Since the Table shows the row percentages of women with a specific characteristic falling into the low, medium and high categories, comparisons are to be made by columns. And, since most of the characteristics are ordinal and increase in "value" of a specific variable, we would expect the

CSP 2010, 37.1-2: 1-23 
percentages under the low status category to decrease and the percentages under the high status category to increase. The percentages under the middle status category may increase or decrease.

A cursory glance at the low status column shows that indeed the percentages decrease for most of the variables. Similarly, the percentages increase under the high status column for most of the variables. In any case, the percentages under the low status column are much higher than in the other two columns confirming our expectation that over 60 percent of Pakistani women would be considered to have low status as measured in this study. The one specific variable that deviates from this pattern is the Respondents' occupation (ROCC). As mentioned earlier, Table 1 also reveals the ambiguity of relationship between scores on status of women and respondents' occupation. Surprisingly, a rather low percentage of women ( 7.8 percent) engaged in good occupations fall into high status category while 26 and 38 percent of women working as laborers or in "prestigious" jobs fall into the same category. Perhaps it is this anomalous situation that deflates the importance of the latent economic dimension in the model seen above. As expected, education of women clearly makes a difference - as education increases, more women fall into the high status category. Even husbands' educational attainment is associated with status of women. More women who work outside their homes and keep what they earn fall into high status than women who don't work or work but do not keep their earnings.

The results also confirm that women who talk with their husbands about family planning matters fall into high status category than women who do not. This is in accordance with our expectations since communication with husband reduces the gender gap and help women to enjoy more equitable relationships which in turn raise their status. The results also confirm the importance and relevance of the two latent dimensions of household decision making and mobility among Pakistani women.

\section{Status of Women and Fertility}

To examine the relationship between fertility and status of women, the latent scores (STATUS) obtained from the structural equation model were used (as a continuous variable) in a path analysis along with five other variables, namely children ever-born (TCEB), age of the respondent (AGE), age at first marriage (AAFM), place of residence (AREATYPE) and exposure to media (EXPMEDIA), the last two as categorical variables. A path from TCEB to STATUS is also included to examine if a woman's status improves with the number of children she has. In the path analysis, both the number of children ever-born (TCEB) and STATUS serve as dependent as well as independent variables. The two independent variables - AAFM and AGE - have direct 
Table 1

Percentages of Women categorized into Low, Medium and High Status by Selected Covariates - PFFPS 1996-97

\begin{tabular}{|c|c|c|c|c|}
\hline \multirow{2}{*}{ Selected Covariates } & \multicolumn{3}{|c|}{ Status of Women } & \multirow{2}{*}{$\mathbf{N}$} \\
\hline & Low & Medium & High & \\
\hline \multicolumn{5}{|l|}{ Respondents' occupation (ROCC) } \\
\hline Not working & 66.5 & 20.2 & 13.5 & 5920 \\
\hline Working as laborers & 50.9 & 23.1 & 26.0 & 1053 \\
\hline Good jobs (jobs better than laborers) & 75.5 & 16.7 & 7.8 & 514 \\
\hline Prestigious jobs & 44.3 & 17.5 & 38.2 & 361 \\
\hline \multicolumn{5}{|l|}{ Respondents' education (REDU) } \\
\hline No education & 72.3 & 17.4 & 10.3 & 5281 \\
\hline Informal or Quranic education & 50.7 & 23.7 & 25.9 & 1122 \\
\hline 8 or less than 8 years of education & 50.2 & 25.7 & 24.2 & 943 \\
\hline 9 or more years or education & 32.5 & 29.9 & 37.6 & 502 \\
\hline \multicolumn{5}{|l|}{ Husband's education (HEDU) } \\
\hline No education & 70.5 & 17.6 & 11.9 & 3383 \\
\hline 5 or less than 5 years of education & 64.7 & 19.2 & 16.0 & 1529 \\
\hline $6-10$ years of education & 56.4 & 23.2 & 20.4 & 1989 \\
\hline 11 or more years of education & 55.1 & 24.0 & 20.9 & 947 \\
\hline \multicolumn{5}{|l|}{ Keep money or not (KEEPM) } \\
\hline Don't work or work but not get paid & 65.2 & 20.2 & 14.6 & 6334 \\
\hline Don’t keep any money & 64.5 & 18.3 & 17.1 & 519 \\
\hline Keep some money & 63.2 & 18.9 & 17.9 & 397 \\
\hline Keep all money & 51.2 & 21.4 & 27.4 & 598 \\
\hline \multicolumn{5}{|c|}{ Family planning talk with husband (FPTALKWH) } \\
\hline Never talked about family planning & 70.0 & 18.8 & 11.2 & 4874 \\
\hline Talked once, twice or sometimes & 54.2 & 22.7 & 23.1 & 1802 \\
\hline Talk often & 53.8 & 21.5 & 24.7 & 1172 \\
\hline \multicolumn{5}{|c|}{ Decision about children's treatment (DTRT) } \\
\hline Others are the decision makers & 78.8 & 14.4 & 6.8 & 6246 \\
\hline Respondent is the decision maker & 6.1 & 42.4 & 51.5 & 1602 \\
\hline \multicolumn{5}{|c|}{ Can go in the vicinity unaccompanied by an adult (CGOUT) } \\
\hline No & 70.7 & 19.4 & 9.9 & 6689 \\
\hline Yes & 24.9 & 24.0 & 51.1 & 1159 \\
\hline
\end{tabular}

CSP 2010, 37.1-2: 1-23 
effects on TCEB, while AGE, AREATYPE and EXPMEDIA have indirect effects on TCEB through STATUS (see Figure 2).

In this framework, place of residence is assumed to influence STATUS, since women living in urban areas generally have more education and higher chance of activities outside their homes. These women are expected to have more equitable relationship with their husbands in discussing fertility and family planning matters compared to women who live in rural areas. A similar argument holds for the variable "exposure to media."

Respondent's age is assumed to explain STATUS directly and then fertility indirectly through STATUS. With increase in age, a woman's position is likely to change as she becomes a mother and then a mother-in-law. Increase in age also reduces the power imbalances between spouses. Moreover, respect, participation in household decision-making and ability to move freely outside the home generally increase with age. Thus, the inclusion of this variable in the path analysis is more to explain the status of women than to explain fertility, which is obvious in the first place.

While Figure 2 shows the standardized path coefficients as is conventionally done, Table 2 presents the unstandardized coefficients of the three regression equations built through this path model. The first is of STATUS, the second is of TCEB and the third is the reduced form connecting STATUS and TCEB. According to the standardized path coefficients in Figure 2, women's age, urban/rural residence and exposure to media explain the status of women significantly, in the given order. As for the total number of children ever-born, respondent's age and age at marriage are significant explanatory variables, in that order. Only two variables - women's status and age at first marriage - have negative effect on the number of children ever born, thus confirming our expectations that women who marry early and who have lower status are likely to have larger number of children. A reciprocal positive association between TCEB and status of women confirms the possibility of considering status of women both as a cause and a consequence of fertility; that is, status of women has negative impact on fertility but number of children has positive impact on status of women (see Balk 1994).

The equations in Table 2 reveal that all the variables included in the model have significant impact on the corresponding dependent variables and in the expected direction. With the few explanatory variables included in the model, we are able to explain only $13 \%$ of variation in the latent variable STATUS, but a much larger percentage $(58 \%)$ of variation in the number of children ever born. 
Figure 2

Standardized Path Coefficients in the Model to Explain Women's Status and Fertility - PFFPS 1996-1997

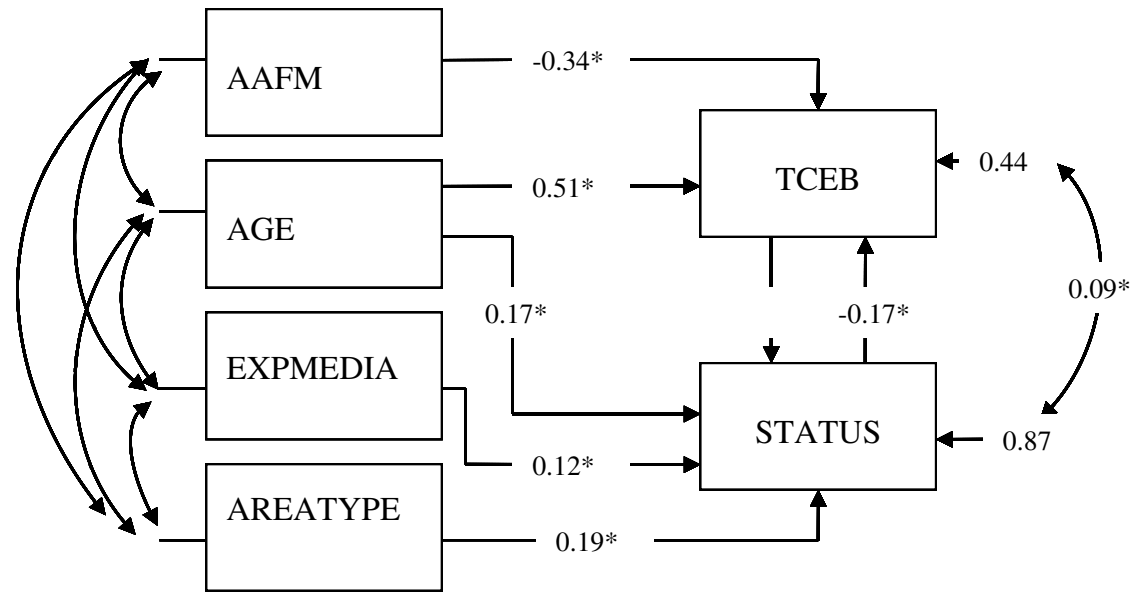

Chi-Square $=2.07, \mathrm{df}=1, \mathrm{P}$-value $=0.15060$, RMSEA $=0.012$

Significance of Coefficients: $*=p<0.01$ 
Table 2

The Estimated Equations (Structural and Reduced) for Status of Women and Children Ever Born for All Women Aged 15-49

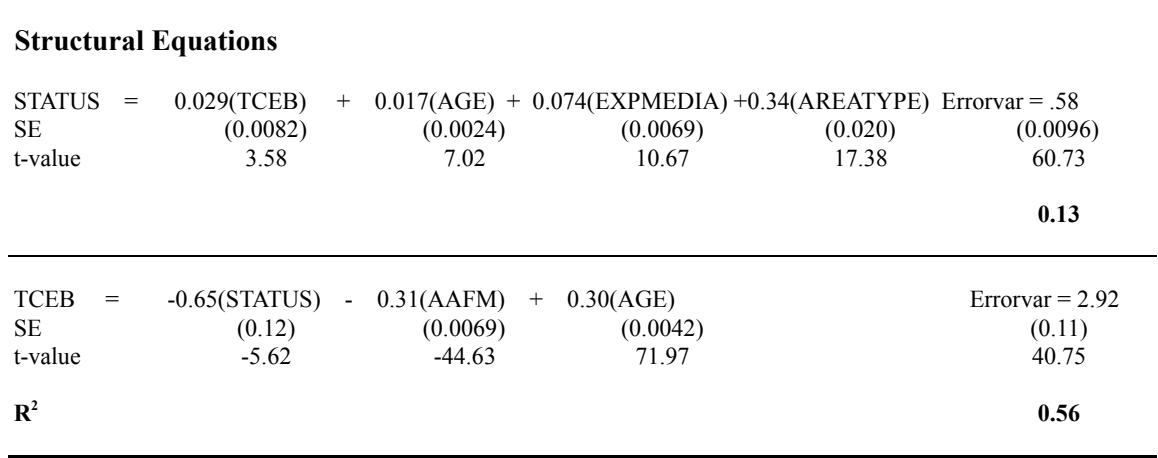

\section{Reduced Form Equations}

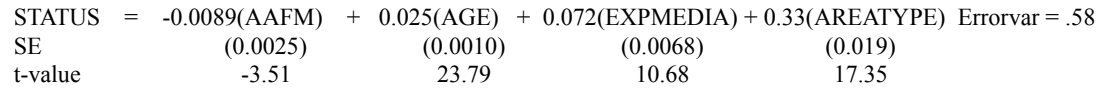

$\begin{array}{lllll}\mathrm{t} \text {-value } & -3.51 & 23.79 & 10.68 & 17.35\end{array}$

$\begin{array}{lr}\mathrm{R}^{2} & 0.13\end{array}$

$\mathrm{TCEB}=-0.30(\mathrm{AAFM})+0.29(\mathrm{AGE})-0.047$ (EXPMEDIA) -0.22 (AREATYPE) $\quad$ Errorvar $=4.22$

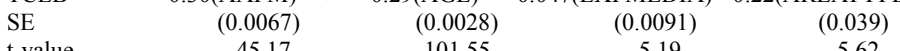

$\begin{array}{lllll}\mathrm{t} \text {-value } & -45.17 & 101.55 & -5.19 & -5.62\end{array}$

$\mathbf{R}^{2}$ 


\section{Summary and Conclusions}

In this study, status of women has been defined and measured by using the ideas currently available in the literature that may not adequately portray women's status in a traditional, patriarchal and Islamic society like Pakistan. Methodologically, however, this study introduces a better way of measuring status of women.

The results presented in this study demonstrate clearly the importance of two factors - women's freedom of mobility and her household decision-making power - which have been cited as the most important indicators of women's status in the literature. Although less important, family planning discussion with others, especially with spouses, is also closely associated with women's status. These socio-demographic indicators play a far greater role in defining Pakistani women's status than the indicators usually associated with human or economic capital.

Women living in urban areas, compared to women living in rural areas, are higher on status because these women have better educational and greater work opportunities, and have more say in household decision-making and greater awareness of modern contraceptives. Exposure to the media can also play a role not only in raising the status of women but also in diffusion of modern ideas regarding fertility control through access and use of contraceptives.

Role of respondent's age, which is proxy of many other factors in social life as well, appeared as an important factor in explaining both status of women and fertility in Pakistan. In a patriarchal society, women's status increases with age as women gain respect and have more authority in all spheres of household decisions. For instance, her relationship to the head of the household shifts over time - from being a wife to becoming a mother - then a mother-in-law, and then a grand mother. The changing relationships are likely to reduce gender gap, improve a woman's position in the household decisions and increase the chances of free mobility. As a result women are more likely to decide independently and move upward in their status.

This study has attempted at measuring the status of women as a latent variable through structural equation modeling. This is distinct from previous studies and has proved to be useful. According to the measurement used in this study, more than 60 percent of Pakistani women are ascribed a low status, which is realistic according to common perception.

It is apparent from the findings that women's status does play a significant role in keeping fertility levels high in Pakistan. This means that raising the status of women will consequently lower the individual as well as overall fertility levels. As the findings indicate, some sort of autonomy, even allowing women to go out unaccompanied by an adult when they want to go, allowing women to seek medical treatment for their children when they are sick,

CSP 2010, 37.1-2: 1-23 
and encouraging them to participate in household decision-making can help raising their status. Expansion of educational opportunities for all, especially for girls, can endow them with more confidence to actively participate in different spheres of activities. Encouraging women to discuss with others, especially with their own spouses, about fertility-related matters can also help bring about fertility reductions in Pakistan.

It is heartening to see that Pakistani government (Women Development Division, Ministry of Women Development) is eager to enhance women's position with its National Policy for Development and Empowerment of Women, envisioning gender equity, socioeconomic and political empowerment of women. This policy aims to remove inequalities by ensuring women's access to all development opportunities and social services, encouraging women's equal participation in national development, decision-making and political processes. This policy also aims to protect women's rights, provide them access to health services, enhance their literacy rates and educational attainment and provide opportunities to use their full potential. However, in the Pakistani context, urban women are likely to benefit more from such a policy since urban areas make it easier to provide services through the available network of roads and infrastructure. In rural areas, lack of resources may restrict the government's ability to provide opportunities accessible to all. Thus, the programs should target women living in rural areas to enhance their position through their active participation in activities outside homes.

In sum, two policy approaches are particularly useful in achieving low fertility levels in Pakistan: one aimed at enhancing the legal and social status of women and increasing their participation in the social and economic domains outside the household; and the other aimed at promoting fertility control directly, reflecting the government's commitment to an antinatalist population policy. It is also possible that structural changes in the society and economy can bring a sharper decline of fertility in this country.

\section{End Notes}

1. According to Bradley and Khor (1993: 350), the term objectification implies "construction of women as sexual objects."

2. In a structural equation model, it is desirable to have at least three indicators to capture a latent variable. Attempts were made to include other indicators available in the PFFPS data set but they were found to be of little value in terms of reliability. We had to be content therefore with these two indicators in the model. 


\section{References}

Aghajanian, Akbar and Amir H. Mehryar. 1999. "Fertility transition in the Islamic Republic of Iran 1976-1996.” Asia Pacific Population Journal 14: $21-42$.

Balk, Deborah. 1994. "Individual and community aspect of women's status and fertility in Rural Bangladesh." Population Studies 48: 21-45.

Balk, Deborah. 1997. "Defying gender norms in rural Bangladesh: A social demographic analysis.” Population Studies 51: 153-172.

Basu, A.M. 1996. "Girls schooling, autonomy, and fertility change: What do these words mean in South Asia?” in Girls Schooling, Women's Autonomy, and Fertility Change in South East Asia. R. Jeffery and A. M. Basu (eds.), New York: Russell Sage Publications. Pp. 48-71.

Birdsall, Nancy and Lauren A. Chester. 1987. "Contraception and the status of women: What is the link?" Family Planning Perspectives 19: 4-18.

Boehmer, Ulrike and John B. Williamson. 1996. "The impact of women's status on infant mortality rate: A cross-national analysis." Social Indicators Research 37(3): 333-360.

Bradley, Karen and Diana Khor. 1993. "Towards an integration of theory and research on the status of women." Gender and Society 7: 347-378.

Cleland, J., N. Kamal, and A. Sloggett. 1996. "Links between fertility regulation and the schooling and autonomy of women in Bangladesh," in Girls Schooling, Women's Autonomy, and Fertility Change in South East Asia. R. Jeffery and A. M. Basu (eds.), Russell Sage Publications. Pp. 205-217.

Curtin, Leslie B. 1982. Status of Women: A Comparative Analysis of Twenty Developing Countries. Population Reference Bureau.

Dixon, Ruth. B. 1978. Rural Women at Work: Strategies for Development in South Asia. Baltimore: John Hopkins University Press.

Dyson, Tim and Mick Moore. 1983. "On kinship structure, female autonomy, and demographic behavior in India." Population and Development Review 9: 35-60. 
Epstein, T Scarlett. 1982. "A social anthropological approach to women's roles and status in developing countries: The domestic cycle," in Interactions between Women's Roles and Population Trends in the Third World. R. M. Anker, M. Buvinic and N. H. Youssef (eds), London: Croom Helm. Pp.151-170.

Folbre, Nancy. 2002. "Of Patriarchy Born: The Political Economy of Fertility Decisions," in Population and Society: Essential Readings. F. Trovato (ed.), Oxford University Press. Pp. 205-214.

Hardee, Karen and Elizabeth Leahy. 2008. Population, Fertility and Family Planning in Pakistan: A Program in Stagnation. Population Action International Working Paper, 4(1).

Hindin, Michelle J. 2000. "Women's autonomy, women's status and fertility related behavior in Zimbabwe." Population Research and Policy Review 19: $255-282$.

Jejeebhoy, Shireen J. 1991. "Women's status and fertility: Successive crosssectional evidence from Tamil Nadu, India, 1970-80." Studies in Family Planning 22: 217-230.

Jejeebhoy, Shireen J. and Zeba A. Sathar. 2001. "Women's autonomy in India and Pakistan: The influence of religion and region." Population and Development Review 27: 687-712.

Mahmud, S. and A. M. Johnston. 1995. "Women's status, empowerment, and reproductive outcomes," in Population Policies Reconsidered. G. S. A. Germain and L. C. Chen (eds.), Boston: Harvard Press. Pp. 151-159.

Mason, Karen O. 1984. The Status of Women: A Review of its Relationships to Fertility and Mortality. New York: The Rockefeller Foundation.

Mason, Karen O. 1986. "The status of women: Conceptual and methodological issues in demographic studies." Sociological Forum 1: 284-300.

Mason, Karen O. and Herbert L. Smith. 2000. "Husband's versus wives' fertility goals and use of contraception: The influence of gender context in five Asian countries." Demography 37: 299-311.

CSP 2010, 37.1-2: 1-23 
McDonald, Peter. 1997. "Gender Equity, Social Institutions and the Future of Fertility." Working Paper in Demography, No. 69. Canberra: Australian National University.

McDonald, Peter. 2000. "Gender equity in theories of fertility transition." Population and Development Review 26: 427-439.

Morgan, S.P. and N. B. Niraula. 1995. "Gender inequality and fertility in two Nepali villages." Population and Development Review 21: 541-561.

PFFPS. 1996-97. Pakistan Fertility and Family Planning Survey Report. National Institute of Population Studies (NIPS), Islamabad, Pakistan.

Ram, Bali. 1993. "Sex differences in mortality as a social indicator." Social Indicators Research 29(1): 83-108.

Sathar, Zeba A. 1996. "Women's schooling and autonomy as factors in fertility change in Pakistan: Some empirical evidence," in Girls Schooling, Women's Autonomy, and Fertility Change in South East Asia.

R. Jeffery and A. M. Basu (eds.), Russell Sage Publications. Pp. 133-149.

Sathar, Zeba. A. 2001. Fertility in Pakistan: Past, Present and Future. United Nations Secretariat: Population Division, Department of Economic and Social Affairs.

Sathar, Zeba A. and John B. Casterline. 1998. "The onset of fertility transition in Pakistan." Population and Development Review 24: 773-796.

Sathar, Zeba A., Nigel Crook, Christine Callum, and Shanaz Kazi. 1988. "Women's status and fertility changes in Pakistan." Population and Development Review 14: 415-432.

Schuler, S.R., S. M. Hashemi and A. P. Riley. 1997. "The influence of women's changing roles and status in Bangladesh's fertility transition: Evidence from a study of credit programs and contraceptive use." World Development 25(4): 563-575.

United Nations. 1975. Status of Women and Family Planning. Report of the Special Rapporteur appointed by the Economic and Social Council under resolution 1326 (XLIV). Department of Economic and Social Affairs, United Nations, New York. 
United Nations. 1993. Women's Status and Fertility in Pakistan: Recent Evidence. New York: Department for Economic and Social Information and Policy Analysis, United Nations.

United Nations. 2004. United Nations International Conference on Population and Development (ICPD). 5-13 September 1994. Cairo, Egypt. http://www.iisd.ca/cairo.html

Visaria, L. 1996. "Regional variations in female autonomy and fertility in India," in Girls Schooling, Women's Autonomy, and Fertility Change in South East Asia. R. Jeffery and A. M. Basu (eds.), Russell Sage Publications. Pp. 235-269.

Vlassoff, C. 1996. "Against the odds: The changing impact of schooling on female autonomy and fertility in Indian village," in Girls Schooling, Women's Autonomy, and Fertility Change in South East Asia. R. Jeffery and A. M. Basu (eds.), Russell Sage Publications. Pp. 218-234.

Wasim, P. M. 2002. "Status of women indicators, infant mortality rate and birth rate: A study of high crude birth rate districts in Pakistan." Indian Economic Review 37: 117-134.

Whyte, Martin King. 1978. The Status of Women in Pre-industrial Societies. Princeton, NJ: Princeton University Press. 


\section{Appendix}

Abbreviations used in the Text, Tables and Figures with their Labels

\begin{tabular}{|c|c|}
\hline Abbreviations & Labels \\
\hline AAFM & Age at First Marriage \\
\hline AGE & Age of Respondents \\
\hline AGFI & Adjusted Goodness of Fit Index \\
\hline AREATYPE & Place of Residence (Urban/Rural) \\
\hline CGOHOS & Women can go Hospital alone to seek medical treatment \\
\hline CGOUT & Can go out (alone) in the vicinity \\
\hline DCLOTH & Decision about Clothing \\
\hline DFID & Department for International Development, United Kingdom \\
\hline DFOOD & Decision about Food (women can participate in decisions about food) \\
\hline DTRT & Decision about Treatment of a child when he/she is sick \\
\hline eco & Economic Dimension \\
\hline EXPMEDIA & Exposure to Media (such as: TV, Newspaper and Radio) \\
\hline fpd & Family Planning Discussion \\
\hline FPDANY & Family Planning Discussion with Anyone \\
\hline FPDWFN & Family Planning Discussion with Friend and Neighbors \\
\hline FPTALKWH & Family Plannig Talk with Husband \\
\hline GFI & Goodness of Fit Index \\
\hline hcap & Human Capital Dimension \\
\hline hdec & Household Decision-making \\
\hline HEDU & Husband's Education \\
\hline $\mathrm{HOCC}$ & Husband's Occupation \\
\hline KEEPM & Keep Money (means that women can possess the money they make) \\
\hline LDCs & Less Developed Countries \\
\hline LSTHM & London School of Hygiene and Tropical Medicine \\
\hline mobil & Mobility \\
\hline NFI & Normed Fit Index \\
\hline NIPS & Natiional Institute of Population Studies, Islamabad, Pakistan \\
\hline PFFPS & Pakistan Fertility and Family Planning Survey \\
\hline REDU & Respondent's Education \\
\hline RMSEA & Root Mean Square Error of Approximation \\
\hline ROCC & Respondent's Occupation \\
\hline STATUS & Status of Women in Pakistan \\
\hline TECB & Total Number of Children Everborn \\
\hline WHAWAY & Working Home or Away from Home \\
\hline
\end{tabular}

CSP 2010, 37.1-2: 1-23 